\title{
Physical Activity and Use of Suburban Train Stations: An Exploratory Analysis
}

Michael Greenberg and John Renne, Rutgers University Robert Lane and Jeffrey Zupan, Regional Plan Association

\section{Abstract}

Physical inactivity contributes to a growing proportion of illness and premature death in the United States. Only about 45 percent of Americans meet the recommended national standard for physical activity. Yet, analysis of 300 surveys collected from train riders at three walkable New Jersey suburban train stations showed that 78 percent met the activity guidelines. A new train station that allows these riders to save time in their commute has attracted new riders and has led existing commuters to change their commute. One-third of those surveyed reported additional physical activity primarily because they walked more after leaving the train in mid-town New York City. Only 8 percent reported less physical activity. The analysis revealed that the new public transit station and personal factors associated with a greater likelihood of using mass transit led to more physical activity.

\section{Introduction}

Providing safe, reliable, and cost-effective mass transportation opportunities has been an unrelenting challenge for transportation planners. With sprawl seemingly devouring open space at a record pace in some metropolitan areas, with traffic congestion a chronic annoyance, and with fuel prices increasing, the opportunity 
for mass transit to make a major difference in the quality of life of many millions of metropolitan residents is apparent. Yet with public budgets severely constrained, the job of increasing mass transit opportunities is daunting.

At the same time, the public health counterparts of transportation planners face the equally challenging objective of controlling obesity. Recent federal guidelines suggest that five days a week of moderately intense activity for 30 minutes or three days a week of vigorous exercise for 20 minutes reduces the chances of diabetes, heart diseases, and other chronic diseases and raises the quality of life (Centers for Disease Control and Prevention [CDC] 1996, 2000, 2001a, 2003a). Yet current data show that most Americans do not meet the guidelines (CDC 2000; 2001a, b; 2003a, b, c; 2004). Mokdad et al. (2004) reported that the combination of poor diet and lack of exercise is the second leading cause of death in the United States and may soon overtake tobacco as the chief cause of death.

Efforts are being made to bring back the formerly strong relationship between urban design and public health (Coburn 2004; Greenberg et al. 1994). In light of these attempts, this article begins with the premise that mass transit increases the likelihood of physical activity for many who walk or bike to the station in the morning and/or after they embark at their final stop. The purpose of this article is to present the results of a study that examined the nexus of rail transit and physical activity. More specifically, the study answered these questions:

1. Do adult train riders engage in more physical activity than the population as a whole?

2. Among train riders, how does physical activity vary according to age, race/ ethnicity, and other demographic and personal characteristics? How does physical activity vary with purpose of trip, origin, and destination of trip?

3. What impact does a modification in transit service have on the physical activity patterns of riders?

\section{Data and Methods}

The study was made of a sample of riders who embarked from three New Jersey Transit (NJT) train stations in Bergen County, New Jersey: Ridgewood, Fairlawn, and Rutherford. The three stations are located along the Bergen line of New Jersey Transit Corporation, the nation's largest statewide public transportation system, offering more than 750,000 daily trips on two light rail lines, 11 commuter rail lines, and 238 bus routes (New Jersey Transit 2004a, b). 
As context, Bergen County has been among the most affluent counties in the United States. For example, in 1989 it ranked fifth (out of more than 3,000) of all U.S. counties in median household income, and has remained an area that has attracted middle-income and affluent people. Ridgewood, Fairlawn, and Rutherford are municipalities of $5.8,3.9$, and 2.8 square miles, respectively, with relatively stable high density (4,300 to 8,200 people per square mile) and middle- and uppermiddle income suburban populations. In 1989, they ranked 19, 182, and 187 out of 566 New Jersey municipal governments in median family income; 15 years later they continue to attract upper-and middle-income residents.

These three train stations were picked to measure the physical activity levels of train riders and to determine what impact a new service would have on physical activity. The stations were selected because they were high ridership stations on one of three lines in Bergen County that would see ridership growth as a result of the new Secaucus Junction Station (SJ), otherwise known as the Frank R. Lautenberg Station. Open for initial passenger use in September 2003, the SJ allows people who commute on the three Bergen County lines to disembark and transfer to the connecting Northeast Corridor Line to Pennsylvania Station in mid-Manhattan, offering an estimated savings of 10 to 15 minutes in each direction (New Jersey Transit 2004a, b; Clary 2003). Passengers also can transfer at the SJ to NJT's main corridor line to Newark, Newark Airport, other points in New Jersey, and beyond to other states by transferring to Amtrak's high speed service in Newark or New York. The station cost $\$ 600$ million and took 15 years from initial planning to completion (Clary 2003). In short, the station was intended to provide another safe, reliable, and convenient component in this already large multimodal transit system.

Fortuitously, the new station also provided an opportunity to examine the impact of changes in transit services on physical activity. That is, people who use the new train station may make adjustments in their commute, which may increase or decrease their physical activity. We expected to find three groups of riders boarding at the three stations. One group of users would not change their commuting patterns because the transfer station does not help them. Nevertheless, we wanted to determine how their physical activity levels compared to residents of New Jersey as a whole to answer the first research question. A second group of riders had used the local train station, but now they also use the transfer station to reach Manhattan faster. We would expect their trip to the station in the morning to be the same. But if they use the transfer station, now they would disembark in a 
different location in New York City. Does a shift in point of disembarkation entail more or less walking for these riders? A third group of riders formerly drove a car or took a bus to work. Were they now more or less engaged in physical activity? If they formerly drove a car and shifted to the train, we assume that they walk more. But if they previously took a bus, they may walk less since they switched to the train.

A three-part survey containing 29 questions (some with multiple parts) was developed to answer the three research questions. Our strategy was to use questions developed for other health-related studies to be consistent with them and to permit easier comparisons with results from other studies. Four questions with a total of nine parts focused on physical activity. The first two were recommended by the CDC and are used to measure physical activity in their behavioral risk factor survey instrument (CDC 2000, 2003a, C).

The first question asks if respondents currently engage in "moderate" physical activity, which is defined as causing small increases in breathing or heart rate. Respondents are asked if they do moderate activity at least 10 minutes at a time. If the answer is yes, they are asked to fill in the number of days per week, and the number of hours and minutes per day they engage in the activities.

The second question repeats the same information for "vigorous" exercise, which is defined as causing large increases in breathing or heart rate. These two sets of questions allowed us to estimate if respondents meet the national guidelines. By using these questions, we were able to compare the results to those for the United States, New Jersey, and another sample taken by Greenberg of 340 New Jersey residents in early 2004.

The third physical activity question was only for respondents who use the SJ. They were asked what impact, if any, the shift to the transfer station has had on physical activity at the beginning of their trip and then after departing the train. Five responses were offered for the front end of the trip: (1) no effect because previously walked same distance to a bus station; (2) no effect because have not changed trip to the train station; (3) would get less exercise because they walked more to get to a bus stop (choice of four options for number of minutes lost is provided); (4) would get more exercise (choice of four length-of-time options is provided); and (5) don't consider any extra minutes gained or loss exercise because they do "real" physical activity at home or elsewhere. 
Four options were provided for the trip home: (1) no effect because pattern of getting to the station has not changed; (2) would get less exercise (choice of four options for number of minutes lost is provided); (3) would get more exercise (choice of four options for number of minutes added is provided); and (4) don't consider any extra minutes gained or loss because they do "real" physical activity at home or elsewhere.

The fourth physical activity question linked walking or biking to the train station to the respondents' perceptions of accessibility to the train station. Specifically, 11 questions defined walkability and bikeability by asking the extent of respondent agreement with a statement (Lane et al. 2003). For example, one question asked if there are sidewalks and places to ride a bicycle the whole way. A second question asked if the sidewalks are in good condition. Other questions addressed safety, automobile traffic, crime, animals, hills, and attractive views. The questions were on a four-point scale ( $1=$ strongly agree, $2=$ =agree, $3=$ disagree, $4=$ strongly disagree). Cronbach's Alpha was used to determine the extent to which these 11 walkability and bikeability measures were correlated. Cronbach's Alpha among the 11 measures was 0.897 . Normally, a Cronbach' Alpha of $>0.7$ is considered good evidence of a single scale, and $>0.8$ is considered excellent evidence of a single scale. This finding means that it was legitimate to compute an aggregate walkable and bikeable scale, which ranged from 11 (strongly disagree with the presence of all walkable and bikeable elements) to 44 (strong agreement with all the 11 elements of walk and bikeability).

Another set of questions provided demographic and other personal data about respondents, including age, gender, type of residence (own, rent), length of residence in the neighborhood, education, race/ethnicity, and number of motor vehicles available to the household. Two questions asked respondents to recall if their parents talked about the importance of physical activity, and if their parents, relatives, and friends walked to work or the train/bus. One question inquired if the respondents felt they had control over risks to their health. The scale for these questions had five points, ranging from "strongly agree" to "strongly disagree." Another question asked how important the train station was in their decision to choose their current place of residence. The choices included "extremely," "somewhat," and "not important."

The final set of questions inquired about respondents' travel patterns. Respondents were queried about the purpose of the current trip, frequency of this kind of trip, and frequency of other uses of public transit. Next, participants were asked 
how they traveled to the train station, where they leave the train, and their final destination (choices were provided, along with an "other" category). Another set of questions focused on participants' knowledge about the transfer station, their current and any future plans to use it, and about factors that might encourage them to use the transfer station. Last, those surveyed who had switched to the S) were asked how they previously made this trip. Prior to gathering the data, we asked several faculty, graduate students, and representatives of CDC to review the instrument and offer comments.

With regard to methods, we used the CDC's definitions of moderate and vigorous physical activity to classify respondents as meeting or not meeting the recommendation. Using these individual yes ( $1=$ met national guidelines) or no $(0=$ did not meet national guidelines) numbers, we calculated an age-adjusted physical activity rate for the sample as a whole. This allowed a direct comparison of these results with U.S. and New Jersey rates calculated by the CDC.

In addition, Greenberg had collected a sample of 340 New Jersey residents using the same physical activity questions. While it is not the focus of this article, we briefly describe it for the record. It was a convenience sample in New Jersey collected by volunteers, targeting places in New Jersey where we could test the expectation that walkability was a more serious problem in distressed urban neighborhoods than in high-quality suburban ones (Greenberg and Renne 2005). The 340 respondents were more likely to be female, renters, high school and college graduates, and Asian or African Americans than New Jersey residents as a whole. But, with regard to physical activity, the convenience sample was not notably different from the state population as a whole.

Although not a random sample, these data were useful because we had access to all the raw exercise data about the people rather than just the rate reported in the literature. In short, the answer to the first research question (physical activity rates of train riders) was obtained by comparing the sample of train riders to the U.S., New Jersey, and the spatially targeted convenience sample of 340 .

With regard to the second research question (correlates of meeting the national physical activity standard), we used binary logistic regression to determine the characteristics of those who met the standard and those who did not. We answered the third research question (net impact of using SJ on physical activity) by examining the responses of all those who used the $\mathrm{S}$ ) and apportioning them among categories of physical activity before and after they began using the transfer station. 
After considering various ways of collecting data over the phone, in person, and via the mail and discussing these options with NJT state officials, the only workable approach was to have someone go to the three train stations and ask people waiting on the platform to fill out the survey. The survey was enclosed in an envelope. Also inside was a cover letter explaining the purpose of the survey and noting that no personal identifiers should be placed on the instrument. A stamped, return envelope and a pencil were provided for the convenience of the respondent.

During April and May 2004, a graduate student went to the Ridgewood station eight times, to Fairlawn eight times, and to Rutherford six times between the hours of 6:30 and 9:30 a.m. during weekdays. In other words, we deliberately wanted to capture the responses of the morning commuters who were more likely to take the train five days a week and hence realize benefits by walking or biking to and from the train station five days a week. So the study had a bias toward daily commuters and not people who took the train during off-hours and on weekends and holidays.

\section{Results}

The graduate assistant approached 709 people. Of those approached, 603 accepted the package. A total of 300 filled out the survey, for a response rate of 49.8 percent. Two forms of sampling bias need to be addressed. One is that the graduate assistant, consciously or unconsciously could have avoided people who appeared to be less fit, or they could have avoided her. We tried to avoid this bias by instructing the assistant to go back a sufficient number of times to make sure that she had an opportunity to speak with every "commuter" she saw on the platform multiple times. A second form of bias could not be avoided. The results show that our respondents were remarkably more physically active than their counterparts in New Jersey and the United States. Part of the reason could be that those who filled out the survey may disproportionately be fit. While we have no evidence to assume that a bias toward more physically active respondents was the case any more than it would be with any sample population, it cannot be dismissed as a possibility and so we need to be careful about generalizing the results.

\section{Respondent Characteristics}

The demographic characteristics of the respondents are compared to the state of New Jersey and the sample of 340 collected by the Greenberg in Table 1. Respondents were more likely to be male and between 31 and 50 years old than were their 
counterparts. They were also more likely to be non-Hispanic whites. A remarkable 85 percent were college graduates, far more than the state proportion.

\section{Table 1. Characteristics of Respondents and Comparison Groups}

\begin{tabular}{|c|c|c|c|}
\hline Characteristic & $\begin{array}{l}\text { Respondents, } \\
\%(n=300)\end{array}$ & $\begin{array}{l}\text { Another } \\
\text { New Jersey } \\
\text { Survey, } 2004 \\
(n=340), \%\end{array}$ & $\begin{array}{l}\text { New Jersey, } \\
2000, \%\end{array}$ \\
\hline \multicolumn{4}{|l|}{ Gender: } \\
\hline Female & 41.6 & 55.1 & 51.5 \\
\hline Male & 58.4 & 44.4 & 48.5 \\
\hline \multicolumn{4}{|l|}{ Homeownership: } \\
\hline Homeowner & 68.9 & 59.8 & 65.6 \\
\hline \multicolumn{4}{|l|}{ Educational attainment: } \\
\hline High school graduate & 99.7 & 92.3 & 82.1 \\
\hline College graduate & 84.5 & 42.4 & 29.8 \\
\hline \multicolumn{4}{|l|}{ Age, years: } \\
\hline $18-30$ & 15.9 & 36.5 & 22.4 \\
\hline $31-50$ & 61.5 & 25.0 & 43.2 \\
\hline $51-70$ & 22.0 & 34.9 & 23.8 \\
\hline $71+$ & 0.7 & 3.6 & 10.6 \\
\hline \multicolumn{4}{|l|}{ Ethnicity -race: } \\
\hline Asian & 6.5 & 9.5 & 5.7 \\
\hline Black & 1.7 & 17.6 & 13.6 \\
\hline Hispanic & 5.1 & 5.5 & 13.3 \\
\hline White, non-Hispanic & 84.4 & 58.5 & 66.0 \\
\hline Other & 2.4 & 8.9 & 1.4 \\
\hline
\end{tabular}

*Data in second data column are from a sample survey taken by Greenberg during the period February-March 2004. Data in third data column are from U.S. Census 2000 counts.

\section{Question 1: Physical Activity Rate}

Table 2 compares rates of physical activity in various combinations of location, gender, and age. The New Jersey age-adjusted rate computed by the CDC from its behavioral risk factor survey was 44.0 (CDC 2000; 2001a, b; 2003a, b, c). The 95 percent confidence limits for that rate were 42.3 and 45.7. For context, the national rate was $45.4(45.0,45.8)$, which means that New Jersey's rate is slightly lower, but not significantly lower than the national one. The physical activity rate of the New Jersey sample of 340 was 42.2 , which is slightly lower than the state rate, but again not significantly lower. The three age-specific rates for the special sample of 340 
show the expected decrease in physical activity with age. In short, the national, New Jersey, and special sample data show that the majority of Americans were not regularly physically active.

In contrast, the 300 surveys from riders at the three train stations show that more than three-quarters of these riders met the physical activity recommendation. The patterns for the group show that age is a factor, but these rates are so much higher than comparative state ones that the oldest age group in the three-station sample has a higher rate of compliance with the national recommendations than the youngest age group for New Jersey as a whole. Indeed, the last row of the table shows that the proportion of respondents who met the survey solely through the vigorous exercise criteria ( $44.6 \%$ ) is about the same as the proportion who met the standard for New Jersey as a whole with the vigorous or the moderate activity criteria.

\section{Table 2. Rates of Physical Activity}

\begin{tabular}{lc} 
Group & $\begin{array}{c}\text { Physical Activity Rate } \\
\text { (95\% confidence limits) }\end{array}$ \\
\hline New Jersey, 2001* & $44.0(42.3,45.7)$ \\
New Jersey sample of 340, 2004** & $42.2(37.0,47.4)$ \\
Age -specific rate, $18-30$ years old & $50.0(40.9,59.1)$ \\
Age-specific rate, 31-50 years old & $43.9(32.9,54.9)$ \\
Age - specific rate, 51-70 years old & $36.5(27.6,45.5)$ \\
Three-station survey, age - adjusted** & $77.6(72.8,82.4)$ \\
Age -specific rate, 18 -30 years old & $85.1(74.5,95.7)$ \\
Age - specific rate, 31-50 years old & $78.0(72.0,84.1)$ \\
Age -specific rate, 51-70 years old & $70.2(72.6,81.4)$ \\
Three-station survey: & \\
Male rate, all ages & $76.9(70.5,83.2)$ \\
Female rate, all ages & $78.1(70.6,85.5)$ \\
Met criteria via moderate activity & $66.8(61.4,72.2)$ \\
Met criteria via vigorous activity & $44.6(39.0,50.3)$ \\
\hline
\end{tabular}

Sources: CDC 2000; 2001a, b; 2003a, b, c.

*This rate is for all the population 18 years and older.

**Rates were age adjusted to New Jersey 2000 population for age group $18-70$.

***Two people were older than 70 and were added to the $51+$ age group to calculate this age-specific rate. 


\section{Question 2: Correlates of Physical Activity}

We performed cross-tabulations of the relationship between the dichotomous physical activity measures with the 24 correlates (Table 3 ). Chi-square tests were used to screen the 24 correlates for statistical significance. Given the exploratory nature of the research, we used $p<0.15$, which is a less restrictive cutoff than is commonly employed $(p<0.05)$. Of the 24,12 were statistically significant at $\mathrm{p}<0.15$. Between 3 and 4 would have been significant by chance $(0.15 \times 24=3.6)$.

Table 3. Correlates of Increasing Physical Activity, Bivariate Analysis

\begin{tabular}{lc|lc}
\hline Correlate & Chi-square & Correlate & Chi-square \\
\hline Homeowner & $4.53^{* * *}$ & $\begin{array}{l}\text { Respondent 18 -30 } \\
\text { years old }\end{array}$ & 1.84 \\
\hline $\begin{array}{l}\text { Make this trip 5 or } \\
\text { more times a week }\end{array}$ & $4.40^{* * *}$ & $\begin{array}{l}\text { Have an advanced } \\
\text { academic degree }\end{array}$ & 1.62 \\
\hline $\begin{array}{l}\text { Transferred at Secaucus } \\
\text { Transfer Station }\end{array}$ & $4.33^{* *}$ & $\begin{array}{l}\text { Train was important } \\
\text { in residential } \\
\text { location decision }\end{array}$ & 1.06 \\
\hline $\begin{array}{l}\text { Boarded at Fairlawn } \\
\text { train station }\end{array}$ & $4.29^{* *}$ & $\begin{array}{l}\text { Recall parents, } \\
\text { friends, and realtives } \\
\text { walking to work }\end{array}$ & 0.73 \\
\hline $\begin{array}{l}\text { Did not graduate } \\
\text { from college }\end{array}$ & $4.21^{* * *}$ & $\begin{array}{l}\text { Household has 0 or } \\
1 \text { auto available }\end{array}$ & 0.24 \\
\hline $\begin{array}{l}\text { Recall parents talking } \\
\text { about importance of } \\
\text { exercise }\end{array}$ & $3.40^{* *}$ & $\begin{array}{l}\text { Trip to the train station } \\
\text { is walk/bikeable }\end{array}$ & $11.15^{* * * *}$ \\
\hline $\begin{array}{l}\text { Current trip is to work } \\
\text { Walk to work after they }\end{array}$ & $3.40^{* *}$ & $\begin{array}{l}\text { Boarded at } \\
\text { Ridgewood station }\end{array}$ & 0.76 \\
leave the train station & $3.10^{* *}$ & $\begin{array}{l}\text { Walked or biked to } \\
\text { the train station }\end{array}$ & 0.16 \\
\hline $\begin{array}{l}\text { Feel that they have control } \\
\text { over own health }\end{array}$ & $2.90^{* *}$ & Graduated college & 0.15 \\
\hline $\begin{array}{l}\text { White respondent } \\
\text { Respondent 51+ years old }\end{array}$ & $2.48^{*}$ & Male respondent \\
\hline $\begin{array}{l}\text { Boarded train at } \\
\text { Rutherford station }\end{array}$ & $\begin{array}{l}\text { Respondent 31-50 } \\
\text { years old }\end{array}$ & 0.10 \\
\hline
\end{tabular}

Chi-square values were statistically significant at $\mathrm{p}<0.05$, $^{* * *} ; \mathrm{p}<.0 .10^{* *}$; and $\mathrm{p}<0.15$. Other variables were not significant correlates.

****Chi-square value of the walk/bikeable variable is high because the variable has 11 values, but variable is not a significant correlate. All the other variables are dichotomous. 
Two of the 12 that were not significant were notable. We had anticipated that those who had parents, friends, and relatives who walked to work or to transit would be more likely to walk to and from the train station. This was not the case. As described below, two other personal variables were significant correlates of meeting the physical activity guidelines and using the train.

We also found that the walk/bikeability index was not associated with walking to the train station. This is an important finding because a great deal of the literature argues that walk/bikeability will promote walking and biking (Humpel et al. 2002; Giles-Corti and Donovan 2002; Leyden 2003, Staunton et al. 2003; Wang et al. 2004). In fact, we did not expect to find a relationship between walk/bikeability to the train station and physical activity because the choice of the three train stations was heavily influenced by anticipated high walk/bikeability. The three stations did have high walk/bikeability scores. Specifically, the previously referred to survey of $340 \mathrm{New}$ Jersey residents asked exactly the same 11 questions about walk and bikeability of people about their own neighborhoods. The range of the walk/bikeability scale is 11 (major problems with all 11 items) to 44 (no problems with any). The average score for the 340 surveys was 22 and the standard deviation was 5.7. With regard to access to the three-station survey, the average score was 35.5 and the standard deviation was 5.8. Another way of interpreting the data is to collapse the four categories (strongly agree, somewhat agree, somewhat disagree, disagree) into two (agree, disagree). This means that the maximum score would be 0 (problems with all 11 walk/bikeability measures) and 11 (agree that all 11 are walk/bikeable). When that calculation was made with these two datasets, the modal response for the 340 New Jersey residents was 7 and the modal response from the 300 who went to the three train stations was a perfect 11 . The average walk/bikeability scores for the Fairlawn, Ridgewood, and Rutherford stations were almost identical. Overall, the lack of predictive ability of the scale was anticipated and in fact was controlled in the study so that it would not confound the results. Briefly, an architect reviewed the three sites and concluded that there are sidewalks/crosswalks on almost every street; there are no significant barriers for walking or biking to the stations, with one exception at Fairlawn; and there are no significant grades above 5 percent. Furthermore, the sites are generally quite aesthetically appealing. Appendix 1 provides detailed data and maps of each of the three stations.

Correlates from the bivariate analyses were entered into a conditional stepwise binary logistic regression with a refinement that the $p$-value to enter was $<0.10$ 
(Table 4). Using the odds ratios to guide the presentation, the portrait showed someone who was most likely to meet the physical activity guidelines and take the train, was not a homeowner ( $O R=0.592)$, nor a college graduate $(O R=2.934)$, and did not leave from the Fairlawn station $(O R=0.461)$. Rather these respondents made the trip at least five days a week $(O R=2.578)$, the trip was for work (OR=9.107), and they used the Secaucus Transfer Station (OR=3.179). Two of these observations are contrary to expectation. Not graduating and not being a homeowner were associated with more physical activity. We had anticipated that these measures of socioeconomic status would be positively associated with physical activity. These observations clearly deserve follow-up because we suspect that there are intervening confounding factors, such as more rental units closer to the train stations.

Yet, the two most interesting observations are that the respondents felt that they had control over their health $(O R=2.265)$ and recalled that their parents talked about the importance of exercise $(\mathrm{OR}=2.044)$. Overall, the simple screening test and the multivariate analysis show that there were interesting differences among the many in this sample who met the physical activity recommendations and the relatively few who did not.

\section{Question 3: Impact of the Transfer Station on Physical Activity}

Comparisons of the impact of the new transit option on physical activity are summarized in Tables 5 and 6 . Half of the respondents who used the new transfer service (39 of 78) reported no change in their physical activity during the morning trip because they walked the same distance to a bus or had not altered their way of getting to the train. Another 26 percent ( 20 of 78 ) said that they did not consider the trip to the train station as physical activity and that they exercised elsewhere. This left 25 percent ( 19 of 78 ) who did report a change in physical activity as a result of using the transfer station. Of these 19, 3 reported less activity and 16 reported more physical activity on the front end of the trip. Most reported 10 to 19 more minutes of physical activity for each trip (Table 5).

With regard to the trip after leaving the train, the impact of switching to the train was more apparent, as anticipated. Sixty percent reported no effect on physical activity or that they did their physical activity elsewhere. But 40 percent (31 of 78) reported an impact on physical activity. Seven of the 31 reported less physical activity and 24 reported more (Table 5). 


\section{Table 4. Binary Logistic Regression of Correlates of Meeting Federal Physical Activity Recommendation}

\begin{tabular}{|c|c|c|c|c|}
\hline Correlate ( $n=299$ cases) & Group & $B$-value & $\begin{array}{l}\text { Std. } \\
\text { Error }\end{array}$ & $\begin{array}{l}\text { Odds } \\
\text { Ratio }\end{array}$ \\
\hline Respondent is a homeowner & $1=$ yes, $0=$ no & -0.524 & 0.354 & 0.592 \\
\hline Make trip five or more times a week & $1=$ yes, $0=$ no & 0.947 & 0.461 & 2.578 \\
\hline $\begin{array}{l}\text { Respondent embarked from Fairlawn } \\
\text { station }\end{array}$ & $1=$ yes, $0=$ no & -0.774 & 0.308 & 0.461 \\
\hline $\begin{array}{l}\text { Feel that he/she has control over } \\
\text { risks to their own health }\end{array}$ & $1=$ yes, $0=$ no & 0.818 & 0.312 & 2.265 \\
\hline Used Secaucus Transfer Station & $1=$ yes, $0=$ no & 1.157 & 0.507 & 3.179 \\
\hline Not a college graduate & $1=$ yes, $0=$ no & 1.076 & 0.524 & 2.934 \\
\hline $\begin{array}{l}\text { Paren ts talked about the importance } \\
\text { of exercise }\end{array}$ & $1=y e s$, no $=0$ & 0.715 & 0.342 & 2.044 \\
\hline Current trip is to work & $1=$ yes, no $=0$ & 2.209 & 1.296 & 9.107 \\
\hline Constant & & -1.997 & 1.398 & 0.136 \\
\hline
\end{tabular}

Summary statistics: Chi-square 36.3, $p<.01$. Pseudo r-square: Cox and Snell 0.115, Nagelkerke 0.175 . The model accurately classified 80.8 percent of the cases into their actual group.

\section{Table 5. Comparison of Physical Activity of Those Who Use the Transfer Station}

\begin{tabular}{lrrrrr}
\hline Change $(n=78 \text { of } 81)^{*}$ & \multicolumn{3}{l}{$\begin{array}{l}\text { Morning Trip to } \\
\text { Work }\end{array}$} & \multicolumn{2}{l}{ Trip Home } \\
& Number & $(\%)$ & \multicolumn{2}{l}{ Num ber (\%) } \\
\hline No effect: Same distance to bus stop & 13 & $(17)$ & NA & \\
\hline $\begin{array}{l}\text { No effect: No change in trip to train } \\
\text { station }\end{array}$ & 26 & $(33)$ & 30 & $(38)$ \\
\hline Don't consider trip physical activity & 20 & $(26)$ & 17 & $(22)$ \\
\hline Less physical activity: 10-19 minutes & 3 & $(4)$ & 7 & $(9)$ \\
\hline More physical activity: & 16 & $(21)$ & 24 & $(31)$ \\
0-9 minutes & 3 & & 11 & \\
$10-19$ minutes & 9 & & 10 & \\
$20-29$ minutes & 3 & & 3 & \\
$30+$ minutes & 1 & & 0 & \\
\hline Total & 78 & $(101)$ & 78 & $(100)$ \\
\hline
\end{tabular}

*Three respondents did not fill out these questions 
Table 6 summarizes the net effect of the daily trips. Almost 6 out of 10 ( 46 of 78 ) respondents reported no net change in physical activity as a result of switching to the Secaucus station. Yet one-third increased their physical activity on one or both ends of the trip and only 7.7 decreased their activity. In other words, more than four times as many increased their physical activity as a result of using the new service than decreased it.

\section{Table 6. Aggregate Results of Physical Activity of Using the Transfer Station}

\begin{tabular}{lcc}
\hline Category & Number & $\%$ \\
\hline More on both ends of the trip & 12 & 15.4 \\
\hline Same on the fro $n t$ and more on the back & 12 & 15.4 \\
\hline More on the front and same on the back & 2 & 2.6 \\
\hline More total & 26 & $(33.3)$ \\
\hline Less on both ends of the trip & 1 & 1.3 \\
\hline Less on the front and same on the back & 2 & 2.6 \\
\hline Same on the front and less on the back & 3 & 3.8 \\
\hline Less total & 6 & $(7.7)$ \\
\hline Less on the front end and more on the back & 0 & 0.0 \\
\hline More on the front end and less on the back & 3 & 3.8 \\
\hline Same on both ends of the trip & 43 & 55.1 \\
\hline No net change, total & 46 & $(59.0)$ \\
\hline Total & 78 & $(100.0)$ \\
\hline
\end{tabular}

\section{Discussion}

The results of this study appear to be relatively straightforward. People who boarded the train at three downtown suburban train stations in middle- to upper-middle income areas of New Jersey are much more likely to be physically active than their counterparts in New Jersey and the remainder of the United States. Included among the factors associated with their physical activity were: (1) a feeling that they have control over their health and (2) their parents talked about the importance of exercise. This suggests that personal psychological factors are important predictors of the incidence of physical activity. Second, the construction of a new rail station that provides a faster alternative to commute to New York City enabling riders to transfer to the high frequency service on the Northeast Corridor line and to reach conveniently located Penn Station in Manhattan has attracted new riders and led others to change their use of the train. 
One-third of these riders have increased their walking typically 10 to 20 minutes in each direction (20-40 minutes overall). This compares to 8 percent who have decreased their walking 20 to 40 minutes a day. In other words, the station has increased the physical activity much more than it has decreased it.

These seemingly straightforward results raise some interesting questions that derive from the findings and from the limitations of this pilot study. First, the stations were deliberately selected because we wanted to study locations where the likelihood of using the new transfer station was high. This meant that three of the most walker- and bicycle-friendly train stations were chosen. Other convenient stations need to be examined to determine if the results of this study are transferable to the larger set of suburban rail stations that appear to be well designed and accessible. We suggest focusing on transit-oriented developments in New Jersey, California, and metropolitan regions of Washington, D.C., and Portland, Oregon, for these replication studies. We also suggest repeating similar studies at bus stations in suburban areas. Furthermore, the geographical focus of this study was suburban downtown train stops. Similar research needs to be performed on transit locations that serve neighborhoods where access to the station is more difficult.

A constraint of the current research was the limited numbers of psychometric measures that could be associated with physical activity and use of transit. The fact that family history and feelings about personal control of health were significant predictors of transit use calls for adding questions about personal efficacy, locus of control, and other measures that would add more about personal feelings regarding the use of transit and physical activity (Furnham and Steele 1993; Lazarus 1991).

Another constraint of concern in the current research was a possible response bias toward people who were physically fit (i.e., people who were less active were less likely to fill out the form). This is our biggest concern about the present study. This possible bias can best be dealt with by obtaining demographic data about all transit users from the organization's files and using that as a basis of comparison in a follow-up. Also, the results show that our respondents were disproportionately physically active, far more than Americans as a whole, New Jersey residents, and the comparative sample. A recent CDC study shows that some of the demographic traits disproportionately represented by our respondents are true of physically active Americans as a whole (CDC 2003c). It is possible that our respondents are a sentinel for the physically active commuters to business and political 
hubs, epitomized by New York City, Philadelphia, Chicago, Washington, D.C, and others across the country.

Because of these intriguing findings, some expected and others not, we suggest that future studies should be designed to look for a link between choice of transit and choice to engage in physical activity. We know that time, cost, comfort, and convenience are traditional factors that help explain the choice of transit versus the private automobile. The high level of physical activity observed at these three stations suggests that we need to ask riders if public health directly or indirectly is a consideration in their choice to use transit. In other words, is there direct cause and effect operating in their decision to take the train. We want to know what weight riders assign to the physical activity they get by walking or bicycling to the station and/or after they leave the station; the importance they assign to using their time on the train to relax, talk to friends, read the newspaper, and think about what they will be doing; and the significance they attach to not driving in a car to work. We also want to know if this population of transit users represents what is commonly called the "healthy worker effect," or, in this case, perhaps the "healthy commuter effect," which implies that they are able to engage in more physical activity than the average adult in the comparison studies because they are not ill. A good way of studying the healthy commuter effect is to compare people who live in the same neighborhoods, work in the same area, and who are similar in socioeconomic status as our respondents. That would be a difficult study to implement, but is possible in some of the major metropolitan areas of the United States.

A striking finding of this study that prompts this suggested research is that the vast majority of these respondents are highly educated and well paid. We assume that they face the kinds of work- and home-related time pressures that would lead them to try to make every minute count. Yet, so many have found the time to exercise and commute on the train that it suggests that they have built a mental model of the value of physical activity and commuting via mass transit that is markedly different from the majority of Americans who do neither and respond by saying that they do not have the time. We believe it would be revealing to conduct in-depth interviews with people who do both in order to understand the kinds of trade-offs they have made (i.e., their mental models of using the train and engaging in physical activity).

Given the findings of this study, it is tempting to assert that transit proponents should add health benefits to convenience, reliability, and safety in their argu- 
ments for transit funding. Yet, it is premature to do so. What is less debatable is for transit systems to tout the physical activity benefits of riding trains and buses versus riding in cars. But we need more than touting. The Secaucus Transfer Station and other rail systems are rare because of their high cost. Adding more bus routes and more frequent buses would give current drivers a chance to walk to a bus. In both the cases of rail and bus routes, physical design alternations and traffic calming methods are likely to be required, especially in difficult-to-navigate city neighborhoods (Greenberg and Renne 2005). Finally, keeping transit fares affordable with subsidies is essential, especially to attract less affluent riders.

More generally, this study underscores the need to realign the fields of planning, design, and public health (Coburn 2004, Greenberg 1994). Urban planning and public health emerged together with the goal of reducing infectious disease outbreaks. The decline of physical activity in the United States and in other autodependent environments is an entrenched problem (Lavizzo-Mourey and McGinnis 2003). Hence, it is encouraging to see university and government researchers, foundations, and the federal government increasingly focusing on this problem. For example, more than 40 articles were published in the American Journal of Public Health (August 2003) and the American Journal of Health Promotion (September/October 2003) about the built environment and public health. Books by Frumkin et al. (2004) and Frank et al. (2003) thoughtfully present the evidence and offer a path forward. These efforts are the first essential steps that must be taken because cutting into the estimated 200,000 to 300,000 deaths a year attributable to this decline of physical activity arguably may be a benefit of providing additional transit opportunities. 


\section{Appendix 1. Secaucus Transfer Activity and Transit Access Study}

\section{Description of Study Area}

\section{Rutherford/East Rutherford}

A. General Description

The Rutherford train station is actually between two municipalities, Rutherford and East Rutherford, which differ somewhat in character. Rutherford is a compact suburb primarily of single-family homes on conventional-sized blocks. Sidewalks are on both sides of almost every block. There is a commercial mixed-use downtown organized along a "main street" (Park Avenue) of primarily retail activities, with offices and some residences above.

East Rutherford, in the train station study area, is less uniform. There are conventional-sized blocks with a mixture of single-family and multifamily dwelling units. However, there are also several places where this pattern breaks down, including:

- several irregularly shaped blocks with industrial uses adjacent to the railroad embankment;

- large undeveloped parcels;

- a large office building complex on an oversized block; and

- a park.

There is some "main street" commercial activity near the station, but at a much smaller scale than downtown Rutherford.

\section{Characteristics of Built Environment}

1. Green Amenity: Within the study area, green surfaces and trees cover approximately 37 percent of the land area.

2. Coverage: Within the study area physical (building "footprints") structures cover approximately 26 percent of the land area.

3. Land Use Mix: Approximate percentages of the total built area are:

Single-family residential: $26 \%$

Multifamily residential: $\quad 15 \%$

Retail $25 \%$

Industrial

Institutional 


\section{RUTHERFORD \\ Secaucus Transfer Health and Activity Study Area}



Regional PlanAssociation

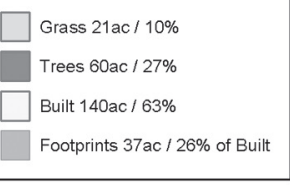


4. Street and Block Pattern Connectivity measures: Intersections per square mile: 225.

\section{B. Train Station Setting and Access}

The train station is an attractive, historic structure. It is very visible from the Rutherford side of the tracks because it is at the terminus of the downtown main street, Park Avenue. The station can be approached from several streets. The station fronts onto a "roundabout"-a small traffic circle. During rush hours there is a lot of traffic because of the confluence of several roads; the traffic tends to be slow moving. There are clearly marked crosswalks. There are also several bus lines that pass through the area in front of the station and some commuters make this intermodal connection.

C. Walking Environment

1. Sidewalks/Crosswalks: There are sidewalks and crosswalks on almost every street.

2. Enhancements and Obstacles: There are no significant barriers for walking and biking to the station. There are bike racks at the station.

3. Topography: There is no significant topography and no grades $>5$ percent.

\section{Fairlawn/Radburn}

A. General Description

The study area can be thought of in quadrants, divided east and west by the tracks and north and south by Fairlawn Avenue. It also is divided east and west by New Jersey State Route 208, which is a limited-access highway. Fairlawn Avenue, the main thoroughfare, is the major connection across the highway to the station.

Fairlawn is distinctive for the Radburn portion of the town plan (in the northeast quadrant). This was conceived and built in the 1920s according to the principles of the Garden City Movement, in particular, around the separation of automobile traffic and pedestrian greenways. Distinctive features include:

- A radial street pattern creates larger than conventional suburban blocks.

- Houses are arranged in compact configurations around cul de sacs that penetrate the edges of the large blocks from the side streets.

- The middle of the block is a shared linear park that is both recreational space and enables residents to reach either the school or a small commercial "downtown" without having to cross more than a few streets. 


\section{FAIRLAWN}

\section{Secaucus Transfer Health and Activity Study Area}

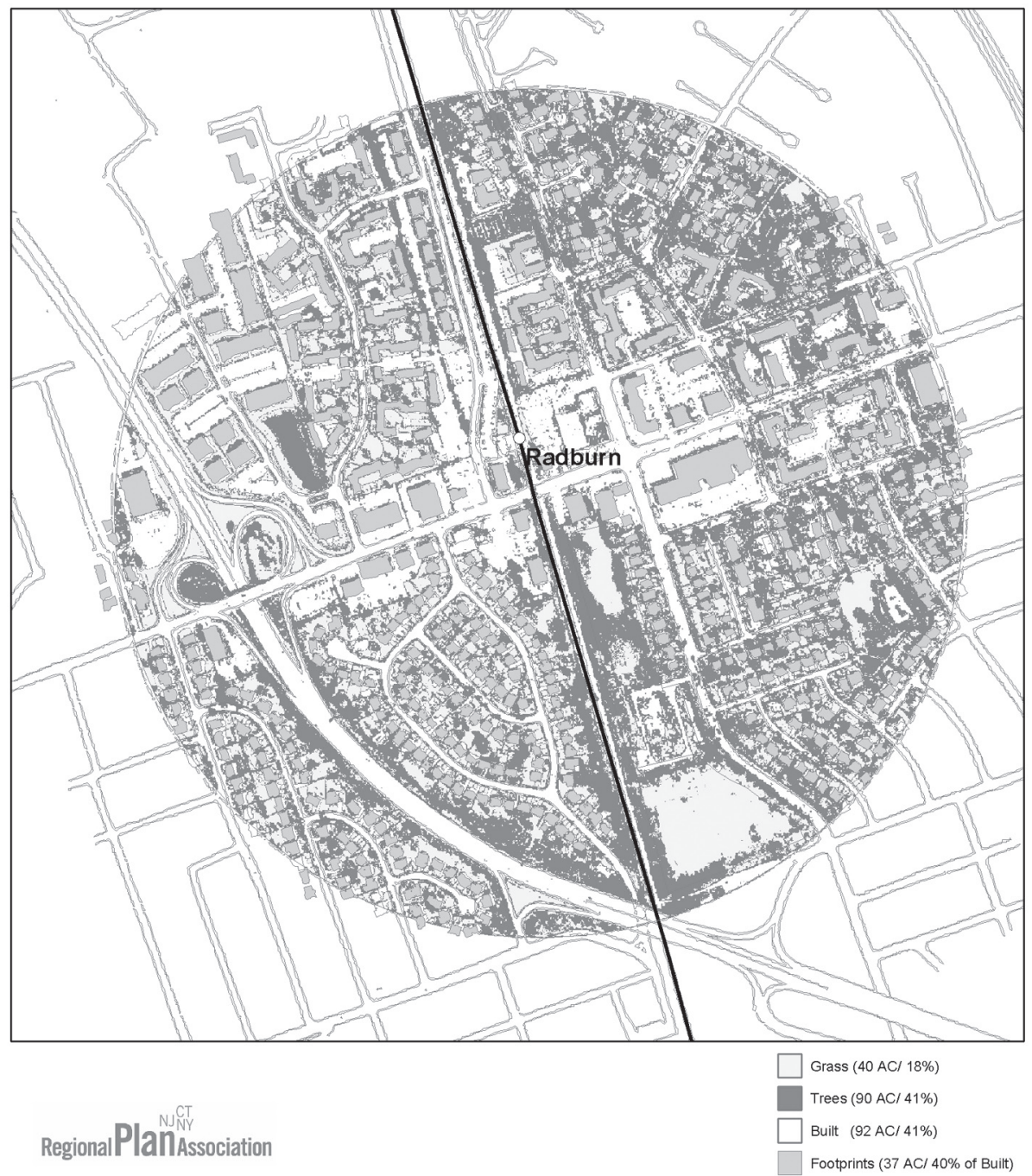


- The original town plan is "transit oriented" in that the streets and greenways lead to the downtown train station, and the station area always was planned as an integral part of the "small downtown."

- There are some apartment buildings close to the downtown and the train station, reflecting the principle that high density should be closer to the station.

Elsewhere east of the tracks and south of Fairlawn Avenue, the street pattern is a conventional street-and-block pattern with primarily single-family homes in compact configurations. There is also some townhouse-type attached housing along Fairlawn Avenue.

On the north side of Fairlawn Avenue between the tracks and Route 208 is a major new high-density townhouse development, approximately $32 \mathrm{du}$ /acre. This is not organized around conventional streets and blocks, but around one or two access roads which lead to parking areas between the buildings.

West of Route 208 is a conventional street-and-block pattern with singlefamily houses on small lots. Because Route 208 curves through here, there are some oddly shaped blocks. There is a large school campus at the southwest edge of the study area. There are light industrial uses adjacent to the west side of the highway north of Fairlawn Avenue.

\section{Characteristics of Built Environment}

1. Green Amenity: Within the study area, green surfaces and trees cover approximately 59 percent of the land area.

2. Coverage: Within the study area physical (building "footprints") structures cover approximately 40 percent of the land area.

3. Land-Use Mix: Approximate percentages of the total built area are:

Single-family residential: $\quad 34 \%$

Multifamily residential: $\quad 30 \%$

Commercial $\quad 12 \%$

Industrial $\quad 1 \%$

Institutional $\quad .7 \%$

4. Street-and-Block Pattern Connectivity Measures: Intersections per square mile: 175. 
B. Train Station Setting and Access

The station is a small historic structure surrounded by lawn and a small parking lot. It is visible from Fairlawn Avenue only within a few blocks of the station. Sidewalks lead directly to the station from Fairlawn Avenue. There are also several bus lines that pass through the area in front of the station and some commuters make this intermodal connection.

C. Walking Environment

1. Sidewalks/Crosswalks: There are sidewalks on most of the streets. Sidewalks are not well defined along edges of the parking lots along Fairlawn Avenue.

2. Enhancements/Obstacles: Route 208 cuts the western part of the study area off from the station, except for Fairlawn Avenue which bridges the highway. There is also a pedestrian connection from the area near the school (southwest) under the highway and across the tracks (at grade).

The greenway network in the residential blocks of the Radburn area (northeast) provides a pleasant link from these blocks to the station area.

3. Topography: There is no significant topography and no grades $>5$ percent.

\section{Ridgewood}

A. General Description

Ridgewood is a compact suburban community on a largely conventional street-and-block network. There is a traditional, mixed-use "downtown," primarily retail uses with offices and apartments above. There are some industrial uses along the south side of the railroad embankment.

North and west of the station, the street pattern is no longer conventional blocks. Instead, a loop road through this neighborhood provides access to a senior apartment complex. While there is no direct road connection to the station from this neighborhood, there is a pedestrian path from the north end of the station platform.

Station Setting: The station, a historic structure, sits in a linear park space straddling the tracks. There is a small surface parking lot on the west side.

The station area (of Rutherford) is the focus of the downtown, and the station is visible at the terminus of Ridgewood Avenue, the "main street." Several bus lines stop at the station area, enabling intermodal connections for commuters. 


\section{Characteristics of Built Environment}

1. Green Amenity: Within the study area, green surfaces and trees cover approximately 50 percent of the land area.

2. Coverage: Within the study area physical (building "footprints") structures cover approximately 40 percent of the land area.

3. Land-Use Mix: Approximate percentages of the total built area are:

Single-family residential: $39 \%$

Multifamily residential: $\quad 12 \%$

Commercial $\quad 39 \%$

Industrial $\quad .9 \%$

Institutional $\quad 6 \%$

4. Street-and-Block Pattern Connectivity Measures: Intersections per square mile: 154.

B. Train Station Setting and Access

The station area is the focus of the downtown, and the station is visible at the terminus of Ridgewood Avenue, the "main street." The station can be approached from several streets. Several bus lines stop at the station area, enabling intermodal connections for commuters.

C. Walking Environment

1. Sidewalks/Crosswalks: There are sidewalks on most of the streets.

2. Enhancements/Obstacles: None are apparent.

3. Topography: There is significant topography in the neighborhood north and east of the station.

\section{Acknowledgments}

We thank two anonymous reviewers for their helpful comments on an earlier version of the paper. 
RIDGEWOOD

\section{Secaucus Transfer Health and Activity Study Area}

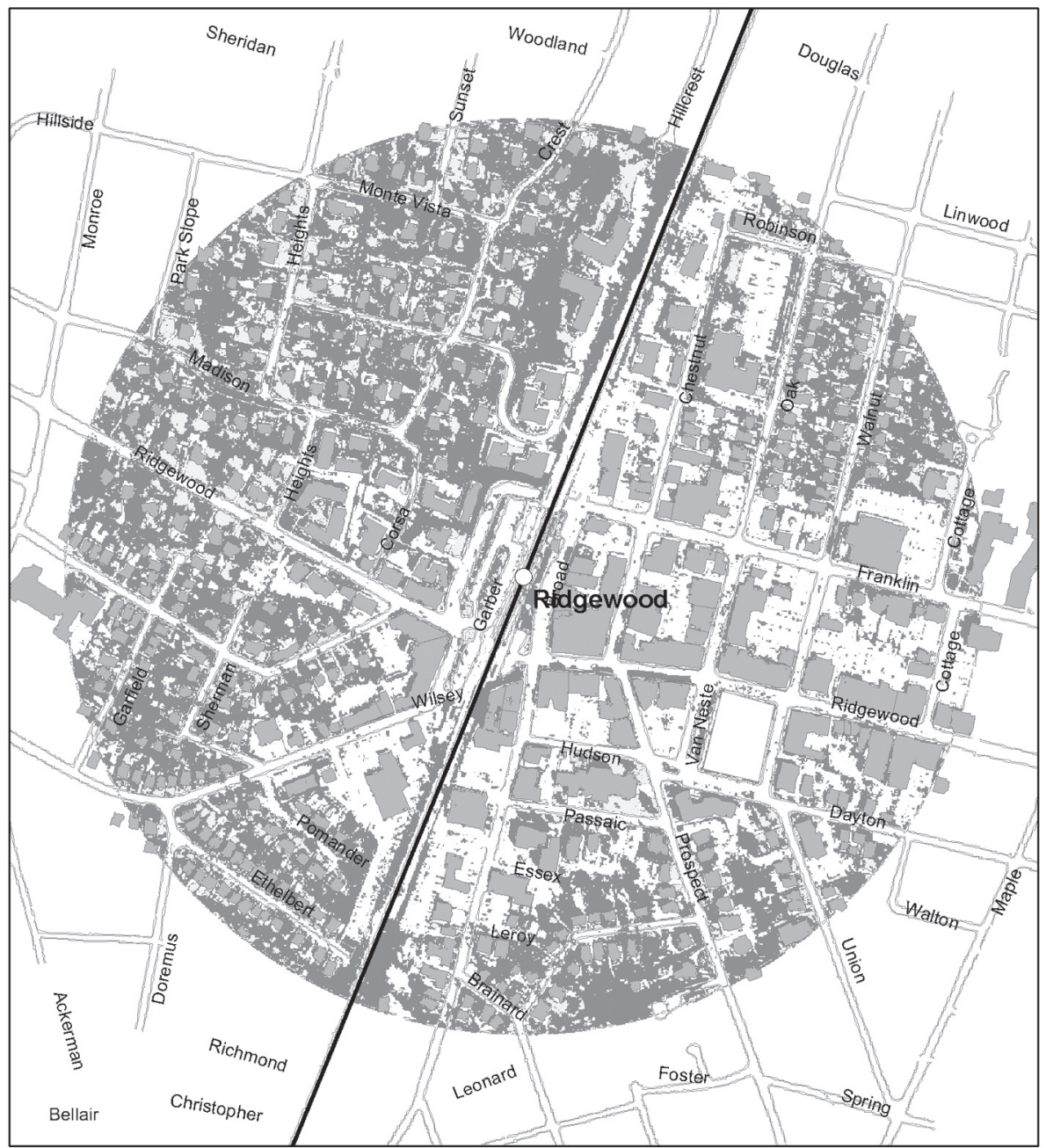

Regional PlantAssociation 


\section{References}

Centers for Disease Control and Prevention. 2004. Prevalence of no leisure time physical activity - 35 states and the District of Columbia, 1988-2002. MMWR $53(4): 82-86$.

Centers for Disease Control and Prevention. 2003a. Prevalence of physical activity, including lifestyle activities among adults-United States, 2000-2001. MMWR 52 (32): 764-769.

Centers for Disease Control and Prevention. 2003b. State-specific prevalence of selected chronic disease-related characteristics-behavioral risk factor surveillance system, 2001. MMWR 52 (SS-8): 560-565.

Centers for Disease Control and Prevention. 2003c. Prevalence of physical activity, including lifestyle activities among adults-United States, 2000-2001. MMWR 52 (32): 764-769.

Centers for Disease Control and Prevention. 2001a. Increasing physical activity, a report on recommendations of the task force on community preventive services. MMWR 50 (RR-18): 560-565.

Centers for Disease Control and Prevention. 2001b. Physical activity trendsUnited States, 1990-1998. MMWR 50 (9): 166-169.

Centers for Disease Control and Prevention. 2000. Compliance with physical activity recommendations by walking for exercise-Michigan, 1996 and 1998. MMWR 49 (25): 560-565.

Centers for Disease Control and Prevention. 1996. Physical activity and health: report of the Surgeon General. Atlanta, GA: U.S. Department of Health and Human Services.

Clary, G. 2003. Secaucus transfer station to open. The Journal News. September 4, 2003. www.nynews.com/newsroom. Accessed June 5, 2004.

Coburn J. 2004. Confronting the challenges in reconnecting urban planning and public health. AJPH 94 (4): 541-546.

Frank, L., P. Engelke, and T. Schmid. 2003. Health and community design: The impact of the built environment on physical activity. Washington, DC: Island Press. 
Frumkin, H., L. Frank, and R. Jackson. 2004. Urban sprawl and public health: Designing, planning and building for healthy communities. Washington, DC: Island Press.

Furnham, A, and H. Steele. 1993. Measuring locus of control: A critique of general, children's health, work-related locus of control questionnaires. British Journal of Psychology 84: 443-479.

Greenberg, M., and J. Renne. 2005. Where does walkability matter the most? An environmental justice interpretation of New Jersey data. Journal of Urban Health 82 (1): 90-100.

Greenberg, M., F. Popper, B. West, B., and D. Krueckeberg. 1994. Linking city planning and public health in the United States. Journal of Planning Literature 8 (3): $235-239$.

Giles-Corti B, and R J. Donovan. 2002. The relative influence of individual, social, and physical environmental determinants of physical activity. Soc Sci Med 54:1793-1812.

Humpel N, N. Owen, and E. Leslie. 2002. Environmental factors associated with adults' participation in physical activity: a review. Am J Prev Med 22: 188199.

Lane R, A. Iton, and S. Blikre. 2003. A healthy community initiative for Stamford. Phase I report, Trumbull, CT, September.

Lazarus, R. 1991. Emotion and adaptation. New York: Oxford University Press.

Leyden, K M. 2003. Social capital and the built environment: the importance of walkable neighborhoods. AJPH 93(9): 1546-1551.

Lavizzo-Mourey R., and J.M. McGinnis. 2003. Making the case for active living communities. AJPH 93 (9): 1386-1388.

Mokdad A.H., J.S. Marks, D. Stroup, and A.L. Gererding. 2004. Actual causes of death in the United States, 2000. JAMA 291: 1238-1245.

New Jersey Transit. 2004a. NJ Transit shortens connections time at Secaucus Junction, press release. www.njtransit.com/ne. Accessed June 5, 2004.

New Jersey Transit. 2004b. Governor opens revolutionary train transfer station in Secaucus. www.njtransit.com/ne. Accessed June 5, 2004. 
Staunton, C, D. Hubsmith, and W. Kallins. 2003. Promoting safe walking and biking to school: the Marin County success story. AJPH 93 (9): 1431-1434.

Wang G, C. Macerca, B. Scudder-Soucie, T. Schmid, M. Pratt, D. Buchner, and G. Heath. 2004. Cost analysis of the built environment: the case of bike and pedestrian trails in Lincoln, Neb. AJPH 94 (4): 549-553.

\section{About the Authors}

Michael GReenberG (mrg@rci.rutgers.edu) is professor and associate dean of the faculty at the Edward J. Bloustein School of Planning and Public Policy at Rutgers University. His research efforts focus on environmental health and risk.

ROBERT LANE (lane@rpa.org) is director of the Design Program at the Regional Plan Association. He is an expert on designing neighborhoods and using art to make places more livable.

JefFREY ZUPAN (jzupan@rpa.org) is a senior fellow at the Regional Plan Association. A former director of planning for NJ Transit, Mr. Zupan has been involved in studying and implementing numerous transportation projects in the New YorkNew Jersey region.

JOHN ReNNE (renne@eden.rutgers.edu) is completing his Ph.D. at the Edward J. Bloustein School of Planning and Public Policy and is studying transit-oriented development. 